Review Article

\title{
A drug will not function unless it is bound to a receptor: a longstanding confusion in basic pharmacology
}

\author{
Partha S. Saha*
}

\author{
Department of Biomedical \\ Sciences, Faculty of Medicine, \\ University of Leuven (KU \\ Leuven), Leuven, Belgium \\ Received: 28 October 2013 \\ Accepted: 13 November 2013 \\ *Correspondence to: \\ Partha S. Saha, \\ Email: \\ p.s.saha.11@aberdeen.ac.uk \\ (C) 2013 Saha PS. This is an \\ open-access article distributed \\ under the terms of the Creative \\ Commons Attribution Non- \\ Commercial License, which \\ permits unrestricted non- \\ commercial use, distribution, \\ and reproduction in any \\ medium, provided the original \\ work is properly cited.
}

\begin{abstract}
The disparity between the general definition of a 'drug' and the wide-spread mechanism of actions of receptor-dependent drugs may often mislead to believe that a drug-receptor interaction is always indispensable for a drug to exert its action. This short review is intended to rectify this basic misconception in pharmacology with the aid of a list of examples of several receptor-independent drugs in context to their mode of actions.
\end{abstract}

Keywords: Receptor-independent drugs, Osmotic diuretics, Keratolytic agent, Chelating agents, Surfactants, Antacid, Protectants and adsorbents, Sucralfate, Laxatives, Cholestyramine, NAC
In pharmacology, receptors help us to understand how numerous drugs act on the body and also to find suitable targets for drugs to bring about their effects in body. Receptors are the cellular macromolecules which regulate the cellular functions when they conjugate with hormones, neurotransmitters, intracellular messengers or any ligands which match with their configurations at binding sites. ${ }^{1}$ According to the definition of WHO, a drug is "a chemical agent that alters the biochemical physiological processes of tissues or organisms." "2 Therefore, it is known that a drug can carry out changes in cellular functions. Besides that if other definition of a 'drug' is looked-upon, it can be understood that drugs are those substances which are not only being used as to cure or treat a disease but also to prevent, mitigate and diagnose a disease. ${ }^{3}$ Hence, it is clear from these two definitions that drugs not only change the biochemical processes inside or outside of cells, but also change the physiological processes of an organism. But it is often considered that all the drugs act by binding with receptors. But here, in this article, it is shown with evidences that some drugs work on the basis of chemical and physical phenomena and bring about changes both chemically and physiologically in a system.
Mannitol and Urea are frequently used as osmotic diuretics. When administered, they happen to stay back in blood, causing an increase in osmotic pressure in blood. This occurs because they are poorly reabsorbed and sometimes never absorbed from the kidney tubules. However, due to the increased osmotic pressure in the blood, the water molecules in blood cannot move out to interstitial spaces. ${ }^{4}$ Therefore, it is clear that these drugs are just exploiting the physical property to carry out its therapeutic effects, without involving any kind of drugreceptor interaction.

Salicylic acid is widely used as keratolytic agent. Keratin is a protein, which acts as an intracellular cementing agent in hyperkeratolytic areas. Salicylic acid reduces the cohesiveness of the intracellular matrix by dissolving the keratin. ${ }^{5}$ It also acts on stratum corneum by reducing the $\mathrm{pH}$ and hydrating it thereby. As a result, it makes the area soft and enhances quick shedding of scales. ${ }^{6}$ This drug, here, acts chemically to treat diseases like psoriasis, corns, calluses, warts, hyperkeratolytic disorders, etc. ${ }^{7}$ 
Calcium chelating agents are used as anti-coagulating agents. They react with the calcium ions, which play an important role in formation of clots, and cause removal of the calcium ions from blood. This leads to the inhibition of clotting of blood. Here, it can be observed again that this reaction involves no receptor; this is occurring solely by chemical reaction. ${ }^{8}$

Certain surfactants are also used as drugs. Molecules of surface-active agents or surfactants are bound to each other irreversibly forming a bi-layer, which is consisted of a hydrophobic non-polar layer and hydrophilic polar layer. With the aid of these two layers, it can orient itself on a compatible interface, causing a drop off of the interfacial energy or tension of the surface. ${ }^{9}$ The pulmonary surfactants, which are made up of specific lipid and proteins, place itself on alveolar and bronchial surface area, lower the surface tension, help in increasing of paracellular permeability by increasing surface area, and thus boost the alveolar-capillary transfer of solutes. Thereby, these type of drugs act on physical phenomena. ${ }^{10}$

The antacid preparations are the well-known over-thecounter drugs. The absorbable antacid creates a protective coating on the surface of esophagus which helps the acid leaking onto it. ${ }^{11}$ On the other hand, aluminium salts, calcium carbonate, magnesium hydroxide, aluminium hydroxide are nonabsorbable antacid agents which are used to neutralize gastric acids. They function in a similar way and do not get bound with any receptors anywhere in the GI tract. They act on the gastric hydrochloride acid, cause partial neutralization and consequently inhibit pepsin, a proteolytic enzyme. ${ }^{12}$ In a process of neutralization, the proton ions from the acid join with counter ions of the salt. This leads in formation of weak acids. The salt again comes to its original form when it interacts with the alkaline environment of duodenum.

Sucralfate is used in anti-ulcer treatment. It is basically aluminium sucrose sulphate complex which when comes in contact with gastric acid changes its physical state to a viscous substance. ${ }^{13}$ This adhesive substance has an affinity towards the defective mucosal layer of GI tract. This affinity is due to an electrostatic bond between positively charged protein layer and negatively charged polyions in its structure. ${ }^{14}$ It can be noticed that this mechanism of action of sucralfate purely dependent on physical phenomena, and there is of course no involvement of receptor action.

Protectants and adsorbents work on the basis of physical phenomena. The protectans are always non-absorbable and the adsorbents can adsorb certain substances. The protectants only lie at the interface of the GI mucosa, protecting the GI line from any erosion in gastro-intestinal tract and sometimes causing distension and irritation which lead to induce vomiting eventually. In contrast, adsorbents tend to adsorb chemicals by creating physical bonds. Kaolin-pectin and bismuth salts are well-known adsorbents. ${ }^{15}$ Additionally, activated charcoal is also a suitable example of adsorbents. It is well understood that neither of these cases involves receptors to act upon. This is occurring by virtue of physical phenomena only.

Laxatives are the drugs to cause the evacuation of bowel. These laxatives are mainly two types: bulk laxatives and osmotically active laxatives. Interestingly, neither of these two types binds with receptors for their actions. Bulk laxatives cause distension of intestinal wall which, in turn, causes activation of the mechanoreceptors. The latter incident induces the greater peristalsis movement. Though the receptors are involved here indirectly, but the nutrients and neither the drugs bind with the receptors. Next comes, the osmotically active laxatives; these laxatives work on the basis of osmotic pressure. These drugs cause water retention inside intestinal fluid; moreover, they themselves do not get reabsorbed in GI tract. These functions are completely devoid of involvement of receptors from any side. Cellulose, agar-agar, linseed are the good examples of the bulk laxatives, and on the other side, mannitol, epsom salt, glauber's salt and lactulose are the examples of the osmotically active laxatives. ${ }^{16}$

Cholestyramine is used as lipid lowering drug. It is actually quaternary ammonium ion exchange resin. This substance has a higher affinity towards the bile salts. It gets conjugated with bile salt electrostatically, forming irreversible bonds. ${ }^{17}$ This is the reason why the complex is insoluble, and because of this it is excreted from body along with faeces. On the other hand, so is to replenish the bile acid concentration in blood, the liver breaks down more and more cholesterol from blood. Thus the cholesterol level in the blood diminishes. ${ }^{18}$ Therefore, it is clearly seen also that the mechanism of action of the Cholestyramine is based on chemical reaction, and there is no involvement of receptors for its action.

Finally, NAC or N-acetylcysteine is used as a mucolytic agent. The sulfhydryl groups of these drugs chemically react with disulfide bond of mucous. As a result of this interaction, the mucous transforms into less condensed form, suggesting clearly involvement of chemical reaction for its mechanism of action all in all. ${ }^{19}$

In conclusion, though most of the drugs depend on receptors for their mechanism of actions, still some drugs are purely dependent on either chemical or physical phenomenon or both. In this point of view, in future if we focus more on discovery and development of receptorindependent drugs simultaneously with the receptordependent drugs, we may find new, potent drugs, offering no or limited side-effects. Nevertheless, before we adapt to this, we must come out of the misconception: drugs only work when they bind with their receptors.

\author{
Funding: None \\ Conflict of interest: None declared \\ Ethical approval: Not required
}




\section{REFERENCES}

1. Neubig RR, Spedding M, Kenakin T, Christopoulos A. International Union of Pharmacology Committee on Receptor Nomenclature and Drug Classification. XXXVIII. Update on terms and symbols in quantitative pharmacology. Pharmacol Rev. 2003 Dec; 55(4):597-606.

2. World Health Organization (WHO). Lexicon of alcohol and drug terms published by the World Health Organization. 2013. Available at http://www.who.int/substance_abuse/terminology/who _lexicon/en/. Accessed on 28 October 2013.

3. Jones PJ and MacKay D. Food \& Drugs : Are there complementary beneficial effects for health? France: Dardaine-leopoli.2010.p8.

4. Okoromah CA, Afolabi BB. Mannitol and other osmotic diuretics as adjuncts for treating cerebral malaria. Cochrane Database Syst Rev 2004;(4):CD004615.

5. Huber C, Christophers E. "Keratolytic" effect of salicylic acid. Archives of Dermatological Research 1977; 257(3):293-297

6. Davies M, Marks R. Studies on the effect of salicylic acid on normal skin. Br J Dermatol 1976; 95(2):18792.

7. Konstantinovic P, Wise RD. Effectiveness of wart removal by compositions including propolis. 1996. US5576005A.

8. Lane CG, Wilson AC, Baugh RF. Platelet function evaluation technique for citrated whole blood. 2001. United States patent: US 62322127 B1.

9. Hills BA. An alternative view of the role(s) of surfactant and the alveolar model. Journal of Applied Physiology 1999; 87(5):1567-83.
10. Schurch S, Lee M and Gehr P. Pulmonary surfactant: Surface properties and function of alveolar and airway surfactant. Pure \&App Chern 1992; 64(11): 1745.

11. National Health Service (NHS). Antacid medicines. 2012. Available at http://www.nhs.uk/conditions/antacidmedicines/Pages/Definition.aspx. Accessed on 28 October 2013.

12. Maton PN, Burton ME. Antacids revisited: a review of their clinical pharmacology and recommended therapeutic use. Drugs 1999; 57(6):855-70.

13. Gorget C. Sucralfate: development of a new concept of anti-ulcer treatment.Review of its pharmacodynamic properties (abstract). Rev Med Interne 1985 Jun;6(3):313-9.

14. Nagashima R. Mechanisms of action of sucralfate. J Clin Gastroenterol 1981;3(2):117-27.

15. Eddlestone SM. Drug Therapies Used in Gastrointestinal Disease. Compendium 2002; 24(6):452-468.

16. Lüllmann H, Hein L, Mohr K and Bieger D. Color Atlas of Pharmacology 2005.3rd ed. New York: Thieme. p174.

17. Thompson WG. Cholestyramine. Canadian Medical Association Journal 1971;104:305-309.

18. Drugs.com. Cholestyramine (Oral route) 2013. Available http://www.drugs.com/cons/cholestyramine.html. Accessed on 28 October 2013.

19. Thorn Research Inc. N-acetylcysteine monograph. Alternative Medicine Review 2000;5(5):467-471.

doi:10.5455/2319-2003.ijbcp20131206

Cite this article as: Saha PS. A drug will not function unless it is bound to a receptor: a longstanding confusion in basic pharmacology. Int $\mathrm{J}$ Basic Clin Pharmacol 2013;2:693-5. 